\title{
AtKP1, a kinesin-like protein, mainly localizes to mitochondria in Arabidopsis thaliana
}

\author{
Cheng Zhi NI*, Hai Qing WANG*, Tao XU, Zhe QU, Guo Qin LIU** \\ State Key Laboratory of Plant Physiology and Biochemistry, College of Biological Sciences, China Agricultural University, \\ Beijing 100094, China
}

\begin{abstract}
Kinesins and kinesin-like proteins (KLPs) constitute a large family of microtubule-based motors that play important roles in many fundamental cellular and developmental processes. To date, a number of kinesins or KLPs have been identified in plants including Arabidopsis thaliana. Here, a polyclonal antibody against AtKP1 (kinesin-like protein 1 in $A$. thaliana) was raised by injection the expressed AtKP1 specific C-terminal polypeptides in rabbits, and immunoblot analysis was conducted with the affinity-purified anti-AtKP1 antibody. The results indicated that this antibody recognized the AtKP1 fusion proteins expressed in E. coli and proteins of $\sim 125 \mathrm{kDa}$ in the soluble fractions of Arabidopsis extracts. The molecular weight was consistent with the calculated molecular weight based on deduced amino acids sequence of AtKP1. To acquire the subcellular localization of the protein, AtKP1 in Arabidopsis root cells was observed by indirect immunofluorescence microscopy. AtKP1 was localized to particle-like organelles in interphase or dividing cells, but not to mitotic microtubule arrays. Relatively more AtKP1 was found in isolated mitochondria fraction on immunoblot of the subcellular fractions. The AtKP1 protein could not be released following a $0.6 \mathrm{M}$ KI washing, indicating that AtKP1 is tightly bind to mitochondria and might function associated with this kind of organelles.
\end{abstract}

Keywords: AtKP1, kinesin-like protein, protein expression, specific antibody preparation, localization, mitochondria.

\section{INTRODUCTION}

Kinesin and kinesin-like proteins (KLPs) constitute a superfamily of microtubule (MT) motor proteins that are found in all eukaryotic organisms. Members of the kinesin superfamily are known to play important roles in many fundamental cellular and developmental processes, such as intracellular transport of vesicles and organelles, spindle formation and elongation, chromosome segregation, MT dynamics, morphogenesis, and signal transduction [1-5]. All members of the kinesin superfamily have a highly con-

\footnotetext{
*These authors contributed equally to this work.

**Correspondence: Guo Qin LIU

Department of Biochemistry and Molecular Biology, College of Biological Science, China Agricultural University, Beijing 100094, China. Tel: +86-10-62733438; Fax: +86-10-62731332;

E-mail: Liu@cau.edu.cn

Abbreviations: FITC (fluorescein isothiocyanate); HEPES [(Na-N(2-hydroxy-ethyl) piperazine-N'-2-ethanesulfonic acid]; IPTG (isopropyl-1-thio- $\beta$-D-galactopyranoside); PIPES, (piperazine-N', Nbis 2-ethanesulfonic acid); PMSF (phenylmethylsulfonyl fluoride); TAME (p-tosyl-L-arginine-methyl-ester); TRITC (tetramethylrhodamine isothiocyanate).
}

served catalytic region of about 350 amino acid residues, known as the motor domain. The motor domain in KLPs is located either in the $\mathrm{N}$-terminus, $\mathrm{C}$-terminus or in the middle of the protein. In addition to the motor domain, most KLPs have a stalk region and a highly variable tail, which is thought to interact with a specific cargo. Stalk and tail regions of different subfamilies of KLPs are not conserved [4].

In early 1990's, plant KLPs were firstly identified in pollen tubes of tobacco $[6,7]$. To date, many KLP cDNA clones have been reported and characterized in several kinds of plants [4]. Systematic analysis of the sequences in Arabidopsis genome with the conserved motor domain of kinesins revealed the presence of 61 KLPs which are divided into three catalogues: $\mathrm{N}$-terminal, C-terminal and internal motors according to the location of kinesin motor domain [8]. However, relatively little is known about their localization and functions [9]. Kat gene family (katA, katB, katC, katD and katE) was characterized in Arabidopsis thaliana [10-12]. KatD belongs to the C-terminal family but with a 240-amino acid stretch following the motor domain, and is a flower-specific motor protein [13]. AtKCBP (kinesin-like calmodulin-binding protein), a novel 
KLP with a C-terminal motor domain, was isolated and characterized in Arabidopsis [14, 15]. Two kinesin-related proteins (AtPAKRP1 and AtPAKRP2) from Arabidopsis are phragmoplast-associated [16, 17]. In addition, another two Arabidopsis KLPs (AtMKRP1 and AtMKRP2) with mitochondrial targeting signals were found in mitochondria [18]. Recently, we have cloned a full-length cDNA (named as AtKP1, kinesin-like protein 1 in A. thaliana) (GenBank accession No. AF398149; AGI No. At3g44730), encoding a kinesin-like protein with high identity to KatD. Here we described the specific antibody raised in rabbit and the subcellular localization of AtKP1 in A. thaliana.

\section{MATERIALS AND METHODS}

\section{Materials}

Seeds of $A$. thaliana (Columbia ecotype) were surface sterilized and germinated at $23^{\circ} \mathrm{C}$ on plates containing murashige and skoog (MS) media supplemental with $3 \%$ sucrose, $0.8 \%$ agar and $0.5 \mathrm{~g} / \mathrm{L}$ [N-Morpholino] ethanesulfonic acid (Mes) ( $\mathrm{pH}$ 5.7). After a further $7 \mathrm{~d}$, seedlings were transplanted to soil and grown in a greenhouse at $23^{\circ} \mathrm{C}$ and $75 \%$ relative humidity.

\section{Isolation of full-length $\boldsymbol{A t K P 1} \mathbf{c D N A}$}

Total RNA was extracted from Arabidopsis stems using TRIZOL reagent (Cat. \#15596, Gibicol, Grand Island, NY, USA) according to the manufacturer's description. First-strand cDNAs were synthesized with a kit from Promega (Madison, WI, USA), and then used as templates for PCR amplification with following primer pairs: forward primer Pkin1, 5'-ATC TTY GCA TAY GGA CAP AC-3', and reverse primer Pkin2, 5'-GTP TAI GGI ATG TCI TTI AGI TTY GAI TG-3', which were designed based on the conserved amino acid sequence in the motor domain of kinesins as described [10].

The 3'RACE-PCR was carried out with the RNA PCR kit (AMV) ver. 3.0 (Cat. \#DRR019, TaKaRa, Dalian, China). Briefly, the first round of PCR amplification was carried out only with the specific forward primer, 5'-GCT GGG TTC GTT TCT AAG GAA-3'. In the second round PCR, both the forward nested primer, 5'-GGC CAG ATC TGA TGA CC-3', and the adaptor primer were included in the mixture with the first round PCR products as templates. Finally, a 3,607 bp cDNA sequence was amplified by RT-PCR with the forward primer, 5'-CCC AAT TTA TTT CCG CGT-3' based on the genome sequence of Arabidopsis information from the GenBank, and the reverse primer, 5'-TGG GAC ACT CGT TCT TTA TGA3 ' based on the sequence of the 3'-end RACE fragment. The fulllength cDNA was cloned into pGEM T-easy vector and sequenced, which contains a stop codon (-72 bp site) upstream of candidate translational initiation codon, a poly A tail at the 3'-end, and an openreading frame of 3,264 bp (denoted as AtKP1, Arabidopsis kinesin protein 1, accession number: AF398149; AGI number: At3g44730).

\section{Expression vector construct}

The coding region $(3,264 \mathrm{bp})$ of AtKP1 was PCR-amplified from the full-length AtKP1 cDNA with following primer pairs: forward primer, 5'-GCG AAT TCT CTA GAA TGG ACC AAG GCG CGA TG-3' and reverse primer, 5'-GCG TCG ACT GGT ACC ATG AAC CTT GCA-3'. The PCR fragment was ligated into pGEM-T easy vector (Cat. \#A1360, Promega, Madison, WI, USA) and se- quence-confirmed. The plasmid was digested with EcoR I/Sal I and the recovered fragment was ligated into the $E c o R \mathrm{I} / \mathrm{Sal}$ I predigested pET-30b(+) vector (Cat. \# 69910-3, Novagen Inc., Madison, WI, USA), so as to a $6 \times$ His-tag coding sequence was fused to AtKPl at $\mathrm{N}$-terminal to result a final construct of pET-AtKP1.

A 606 bp DNA fragment corresponding to nucleotides 2656 to 3261 of AtKP1 full-length cDNA was PCR-amplified using the following primer pairs: forward primer, 5'-GCC ATA TGC TTC ACA CTG ATA ACT CTT CA-3'; reverse primer, 5'-GCG TCG ACT GGT ACC ATG AAC CTT GCA-3'. The PCR fragment was digested with $\mathrm{Nde}$ I and $\mathrm{Sal}$ I and ligated into the $\mathrm{Nde}$ I-Sal I predigested pET-30b(+) vector, so as to be in frame with the sequence encoding the histidine hexamer to form a final construct of pET-KA which will give a $28 \mathrm{kDa}$ AtKP1-specific polypeptide as an antigen.

\section{Expression and purification of recombinant proteins}

The recombinant plasmids were transformed into E. coli BL21 (DE3) strain. The transformants were grown at $37^{\circ} \mathrm{C}$ to $\mathrm{A}_{600}=0.6$ $\mathrm{OD}$ and subsequently induced with $0.2 \mathrm{mM}$ IPTG for $4 \mathrm{~h}$ at $25^{\circ} \mathrm{C}$. The cells were harvested and sonicated on ice in buffer A ( $20 \mathrm{mM}$ Tris-HCl, $\mathrm{pH} 7.5,150 \mathrm{mM} \mathrm{NaCl}, 1 \mathrm{mM}$ PMSF). The proteins from E.coli expressing AtKP1 were suspended in $1 \times$ SDS sample buffer for SDS-PAGE and western blot analysis. The prokaryotic expressed AtKP1-specific polypeptide was affinity-purified with Ni-Chelating-Sepharose Fast Flow (Cat. \#17-0575-01, Amersham Pharmacia, Uppsala, Sweden) as described by the manufacturers. All subsequent steps were performed at $4^{\circ} \mathrm{C}$. After the bacteria cell extract was centrifuged at $12,000 \times \mathrm{g}$ for $30 \mathrm{~min}$, the resultant supernatant was applied to a self-packed $1 \mathrm{ml} \mathrm{Ni-resins} \mathrm{pre-equilibrated} \mathrm{with} \mathrm{buffer}$ A. After washing with $100 \mathrm{mM}$ imidazole in buffer A, the His-tagged fusion protein was eluted with $300 \mathrm{mM}$ imidazole in buffer A.

\section{Preparation of anti-AtKP1 polyclonal antibody}

The purified His-tagged AtKP1-specific polypeptide was used as antigen to raise polyclonal antibodies in a female New Zealand white rabbit. Sera were passed through a DEAE-cellulose 52 column to obtain whole $\operatorname{IgG}$. The antibodies specific to AtKP1 were further affinity-purified by a blot purification method [19], and applied to immunobloting or immunolocalization.

\section{Protein extraction from plant tissues}

Roots, stems, leaves, flowers, siliques (28-day-old) and young seedlings (7-day-old) of Arabidopsis were frozen and ground in liquid nitrogen. Proteins were extracted from tissues with a buffer containing $100 \mathrm{mM}$ HEPES (pH 7.8), 5 mM EDTA, 5 mM EGTA, 10 $\mathrm{mM} \mathrm{Na} \mathrm{VO}_{4}, 10 \mathrm{mM} \mathrm{NaF}, 50 \mathrm{mM}$ glycerol-phosphate, $10 \mathrm{mM}$ DTT, 5\% glycerol, $1 \mathrm{mM}$ PMSF, $10 \mathrm{mg} / \mathrm{ml}$ Leupeptin, $10 \mathrm{mg} / \mathrm{ml}$ Aprotinin, and $10 \mathrm{mg} / \mathrm{ml}$ Antipain on ice. The extract was then centrifuged at $20,000 \times \mathrm{g}$ at $4^{\circ} \mathrm{C}$ for $40 \mathrm{~min}$, and the supernatant were analyzed by SDS-PAGE and Western blot.

\section{Subcellular fractionation}

Organelles were isolated from Arabidopsis leaves by differential and sucrose density-gradient centrifugation as described by Laties [20] with some modification. All subsequent procedures were performed at $4^{\circ} \mathrm{C}$. Leaves were homogenized with a tight-fitting homogenizer in ice-cold medium A consisting of $100 \mathrm{mM}$ Tricine-KOH (pH 7.4), $300 \mathrm{mM}$ sucrose, $10 \mathrm{mM} \mathrm{KCl}, 1 \mathrm{mM} \mathrm{MgCl}, 1 \mathrm{mM}$ potassiumEDTA, 0.1\% BSA, 5 mM DTT, 1 mM PMSF, $10 \mathrm{mg} / \mathrm{ml}$ Leupeptin, 10 
$\mathrm{mg} / \mathrm{ml}$ Aprotinin, $10 \mathrm{mg} / \mathrm{ml}$ Antipain, $10 \mathrm{mg} / \mathrm{ml}$ pepstatin A, and 10 $\mathrm{mg} / \mathrm{ml}$ TAME. The homogenate was filtered through four layers of cheesecloth and centrifuged at $2,600 \times \mathrm{g}$ for $15 \mathrm{~min}$ to pellet the cell debris and nuclei. The 2,600 $\times$ g-supernatant was spun for $15 \mathrm{~min}$ at $12,000 \times \mathrm{g}$ and the pellet was resuspended in medium B similar to medium A, but without DTT and at $\mathrm{pH} 7.0$ instead of 7.4. About 2 $\mathrm{ml}$ of organelle suspension was layered on top of a sucrose gradient containing $6 \mathrm{ml}$ of $0.6 \mathrm{M}, 4 \mathrm{ml}$ of $0.9 \mathrm{M}, 8 \mathrm{ml}$ of $1.2 \mathrm{M}$ sucrose, $8 \mathrm{ml}$ of $1.45 \mathrm{M}$ and $8 \mathrm{ml}$ of $1.8 \mathrm{M}$ sucrose. The gradient was spun at 80 , $000 \times \mathrm{g}$ for $90 \mathrm{~min}$. The fractions were collected and identified by measuring activities of marker enzymes, including cytochrome $c$ oxidase for mitochondria, inosine 5'-diphosphatase (IDPase) for Golgi apparatus, catalase for peroxisomes, and chlorophyll for chloroplasts. Enzyme activities were determined by standard colorimetric methods [21]. Chlorophyll was determined using the protocol of Arnon [22]. The $12,000 \times \mathrm{g}$ supernatant was centrifuged for $40 \mathrm{~min}$ at 150 , $000 \times g$ to isolate cytosol and microsomes according to the method of Khodjakov et al [23].

\section{Extraction of peripheral proteins from mitochondria}

Two of $300 \mu \mathrm{l}$ mitochondria fraction recovered from the sucrose density gradient were diluted 5-fold with medium B (mentioned as above) and spun at $12,000 \times \mathrm{g}$ for $15 \mathrm{~min}$ at $4^{\circ} \mathrm{C}$ to precipitant mitochondria. One of the mitochondria pellets was resuspended in $50 \mu 12 \times$ SDS sample buffer, the other was used for mitochondria peripheral protein isolation. For this, it was incubated for $30 \mathrm{~min}$ on ice with $30 \mu 10.6 \mathrm{M} \mathrm{KI}$ and centrifuged at $100,000 \times \mathrm{g}$ for $30 \mathrm{~min}$ at $4^{\circ} \mathrm{C}$ [24]. The KI-washed mitochondria supernatant was mixed with $20 \mu 15 \times$ SDS sample buffer and the KI-washed mitochondria pellet was resuspended in $50 \mu 12 \times$ SDS sample buffer. Equal volumes of mitochondria proteins, KI-washed supernatants, and KI-washed pellets were analyzed by immunobloting.

\section{Immunofluorescence localization}

Immunofluorescence experiments were carried out according to Lee et al [17]. Root tips excised from 7-day-old seedlings were fixed in $4 \%$ paraformaldehyde plus $0.1 \%$ glutaraldehyde in PME $(50 \mathrm{mM}$ Pipes, $1 \mathrm{mM} \mathrm{MgSO}$, and $5 \mathrm{mM}$ EGTA, pH 6.9) for $1 \mathrm{~h}$, rinsed several times in PME and treated with 1\% Cellulase "Onozuka" RS (R-10) (Yakult Honsha Co., Ltd., Tokyo) and 0.5\% Pectolyase (Cat. \# P5936, Sigma, St. Louis, MO, USA) in PME for $15 \mathrm{~min}$. After rinsing, cells were released by squashing on slides coated with $1 \mathrm{mg}$ / $\mathrm{ml}$ poly-L-lysine described previously by Palevitz [25]. After airdried, the cells were treated with prechilled methanol for $6 \mathrm{~min}$, followed by treatment with $0.5 \%$ Triton $\mathrm{X}-100$ for $30 \mathrm{~min}$ and $1 \%$ BSA in PBS for another $30 \mathrm{~min}$. The affinity-purified anti-AtKP1 antibody was applied at a 4-fold dilution in PBS (0.135 M NaCl, 2.7 $\mathrm{mM} \mathrm{KCl}, 1.47 \mathrm{mM} \mathrm{KH}_{2} \mathrm{PO} 4,8.1 \mathrm{mM} \mathrm{Na}_{2} \mathrm{HPO} 4, \mathrm{pH} 7.3$ ) in combination with a 400 -fold dilution of anti- $\beta$-tubulin monoclonal antibody (Cat. \#T5293, Sigma, St. Louis, MO) for $1 \mathrm{~h}$ at room temperature. Secondary antibodies were FITC-conjugated goat anti-rabbit IgG (Cat. \#F0382, Sigma, St. Louis, MO) and TRITC-conjugated goat anti-mouse IgG (Cat. \#115-025-003, Jackson ImmunoResearch Labs, West Grove, PA, USA), both diluted 100-fold. Images were acquired with a Confocal Laser Scanning Microscope (Bio-Rad, Hercules, CA).

\section{SDS-PAGE and Western blot}

Proteins were separated on SDS-PAGE according to Laemmli
[26], and then stained with Coommasie blue $\mathrm{R}_{250}$ or electroblotted onto nitrocellulose membrane (Hybond-c, Amersham) at $30 \mathrm{~V}$ for $8 \mathrm{~h}$ followed by $50 \mathrm{~V}$ for $40 \mathrm{~min}$. After blocked in 5\% nonfat milk in TBS (20 mM Tris-HCl, pH 7.5, $30 \mathrm{mM} \mathrm{NaCl}$ ) supplemented with $0.05 \%$ Tween-20, the membranes were incubated with mouse anti-His monoclonal antibody (1:5000 dilution), or mouse anti-kinesin monoclonal antibody (Cat. \#K1005, Sigma, 1:5000 dilution) or mouse anti-âactin monoclonal antibody (Cat. \#A5441, Sigma, 1:5000 dilution), or our purified rabbit anti-AtKP1 polyclonal antibody (1:40 dilution). Following three washes, the membranes were incubated with peroxidase-conjugated goat anti-mouse (or anti-rabbit) IgG (Cat. \#115035-003, \#111-035-003, Jackson ImmunoResearch Labs, West Grove, PA; 1:5000 dilution). The membranes were visualized by using an enhanced Lumi-Light Western Blotting Substrate kit (Cat. \#2015200, Roche, Indianapolis, IN, USA) and following the manufacturer's instruction.

\section{RESULTS \\ Generation and specificity assay of a polyclonal anti- body against AtKP1}

Rabbit antiserum was raised using the prokaryotic ex-

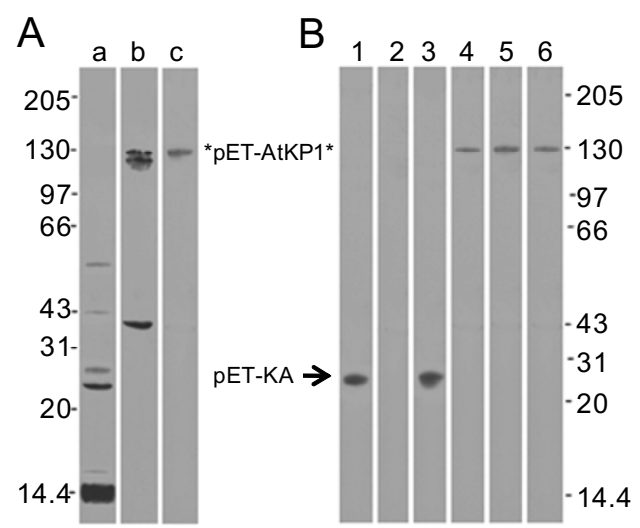

Fig. 1 Characterization of the anti-AtKP 1 antibody by immunoblotting. (A) Proteins from Arabidopsis shoots were separated on a $7.5 \%$ SDS-PAGE gel ( $40 \mu \mathrm{g}$ protein per lane) and transferred onto nitrocellulose membrane. Total proteins on blots were probed with pre-serum (lane a), antiserum (lane b), and affinitypurified anti-AtKP1 antibody (lane c). (B) Western blot of the E. coli lysates containing either the His-tagged AtKP1-specific antigen or the entire AtKP1 polypeptides. Lanes 1 to 3 are the immunoblots of His-tagged AtKP-specific polypeptide probed with monoclonal anti$6 \times$ histidine antibody (lane 1), monoclonal anti-kinesin antibody (lane 2), and affinity-purified anti-AtKP1 antibody (lane 3), respectively; Lanes 4 to 6 are the immunoblots of His-tagged AtKP1 probed with the antibodies including anti- $6 \times$ histidine antibody (lane 4 ), kinesin antibody (lane 5), as well as our affinity-purified AtKP1 antibody (lane 6). Asterisks indicate the $125 \mathrm{kDa}$ AtKP1 and the arrow indicates the $28 \mathrm{kDa}$ AtKP1-specific polypeptide. The positions of molecular mass markers (in kilodaltons) are indicated on the left in (A) and on the right in (B). 
pressed His-tagged polypeptide (residues 886-1087, 28 $\mathrm{kDa}$,) that is unique to AtKP1. The antibody was affinitypurified and its specificity was identified.

As shown in Fig.1A, the antiserum reacts with several polypeptides in extract of whole Arabidopsis shoots (Fig. $1 \mathrm{~A}$, lane $\mathrm{b}$ ), among which only the one with a molecular weight of $125 \mathrm{kDa}$, the size predicted from cDNA sequences of AtKP1, could be recognized by the affinitypurified anti-AtKP1 (Fig 1A, lane c). To verify whether the $125 \mathrm{kDa}$ polypeptide was AtKP1, we prepared the $E$. coli $\mathrm{BL} 21$ lysates containing the $28 \mathrm{kDa}$ AtKP1-specific polypeptides encoded by pET-KA or His-tagged entire AtKP1 encoded by pET-AtKP1. When subjected to immunoblotting with monoclonal anti- $6 \times$ histidine antibody (Fig. 1B, lanes 1 and 4), monoclonal anti-conventional kinesin antibody (Fig. 1B, lanes 2 and 5), and our affinitypurified anti-AtKP1 (Fig. 1B, lanes 3 and 6) respectively, the lysate containing the AtKP1-specific polypeptide produced a single immunoreactive band with a $M_{r}$ of $28 \mathrm{kDa}$ (Fig. 1B, lanes 1 and 3), corresponding to the specific polypeptides used as antigen that could not be recognized by the anti-conventional kinesin antibody (Fig 1B, lane 2),

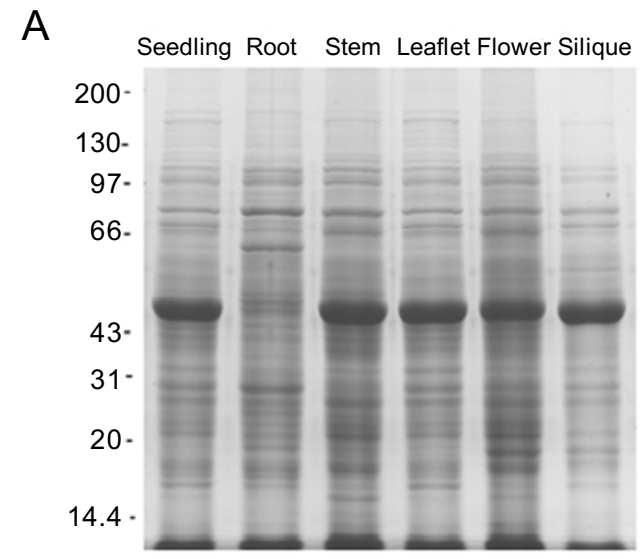

B

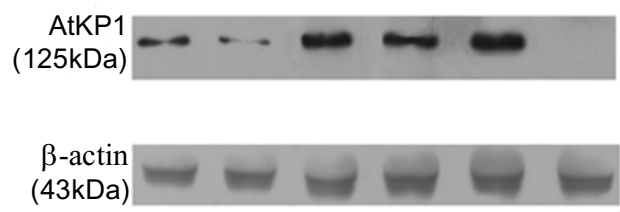

Fig. 2 The expression detection of AtKP1 in different tissues. (A) SDS-PAGE analysis of proteins from each organ of Arabidopsis. Each lane contains $40 \mu \mathrm{g}$ of total proteins extracted from seedlings, roots, stems, leaflets, flowers, and siliques. (B) Immunoblot analysis of AtKP1 with affinity-purified AtKP1 antibody to total proteins described as above. The lower panel shows anti- $\beta$-actin antibody labelling in the corresponding nitrocellulose membrane, confirming the presence of equal amounts of total proteins in each lane. and the lysate containing the whole AtKP1 produced a 125 $\mathrm{kDa}$ bands (Fig. 1B, lanes 4-6). The results above indicate that our affinity-purified anti-AtKP1 antibody is specific for Arabidopsis AtKP1.

\section{Detection of AtKP1 in different tissues}

The expression of AtKP1 protein in Arabidopsis tissues was examined by immunoblot analysis with affinity-purified anti-AtKP1 (Fig. 2). A single band corresponding to the AtKP1 protein with a molecular size of $125 \mathrm{kDa}$ was detected in total protein extract of seedlings, roots, stems, leaflets, flowers; but no such band was detected in siliques (Fig. 2B).

The relative amount of AtKP1 was quantitatively estimated for each organ. The samples were normalized, so that approximately equal amounts of total protein were loaded on a gel. When analyzed in immunoblotting, the blots were incubated with the antibodies against AtKP1specific polypeptide and $\beta$-actin, so that the relative amount of AtKP1 from each organ could be determined using the relative amount of the $\beta$-actin as a reference point. The results show that AtKP1 was the highest enriched in flowers, and then in stems, leaves, roots in turn.

\section{Immunofluorescence localization of AtKP1}

Arabidopsis root tip is liable for immunofluorescent labeling, especially for the proteins in whole cells at different dividing phases. To get the distribution of AtKP1 in detail, single root tip cells at different phases of cell division were dually immunostained using affinity-purified AtKP1 antibody and anti- $\beta$-tubulin monoclonal antibody.

In interphase cells, AtKP1 was present throughout the cytoplasm (Fig. 3A-C). In preprophase cells, microtubules reorganized to form preprophase bands, but AtKP1 still localized to particle-like structures (Fig. 3D-F). In metaphase cells, no AtKP1 was detected on spindle microtubules (Fig. 3G-I). When microtubules concentrated to form phragmoplast, AtKP1 still keeps staying throughout the cytoplasm (Fig. 3J-L). The results demonstrate that AtKP1 does not correlate with mitotic microtubule organization as most other plant KLPs, but associates with some kinds of organelles.

\section{Subcellular fractionation and identification}

From the results of immunofluorescence microscopy, we know that AtKP1 is present on particle-like organelles in cytoplasm. In order to reveal the detail localization, we fractionated mitochondria, microsomes, chlorophyll, and cytosol from Arabidopsis leaves by sucrose density gradient ultracentrifugation and analyzed these subcellular fractions by Western blot with AtKP1 antibodies. As shown in Fig 4A (lane 8), AtKP1 was only found in mitochondria 

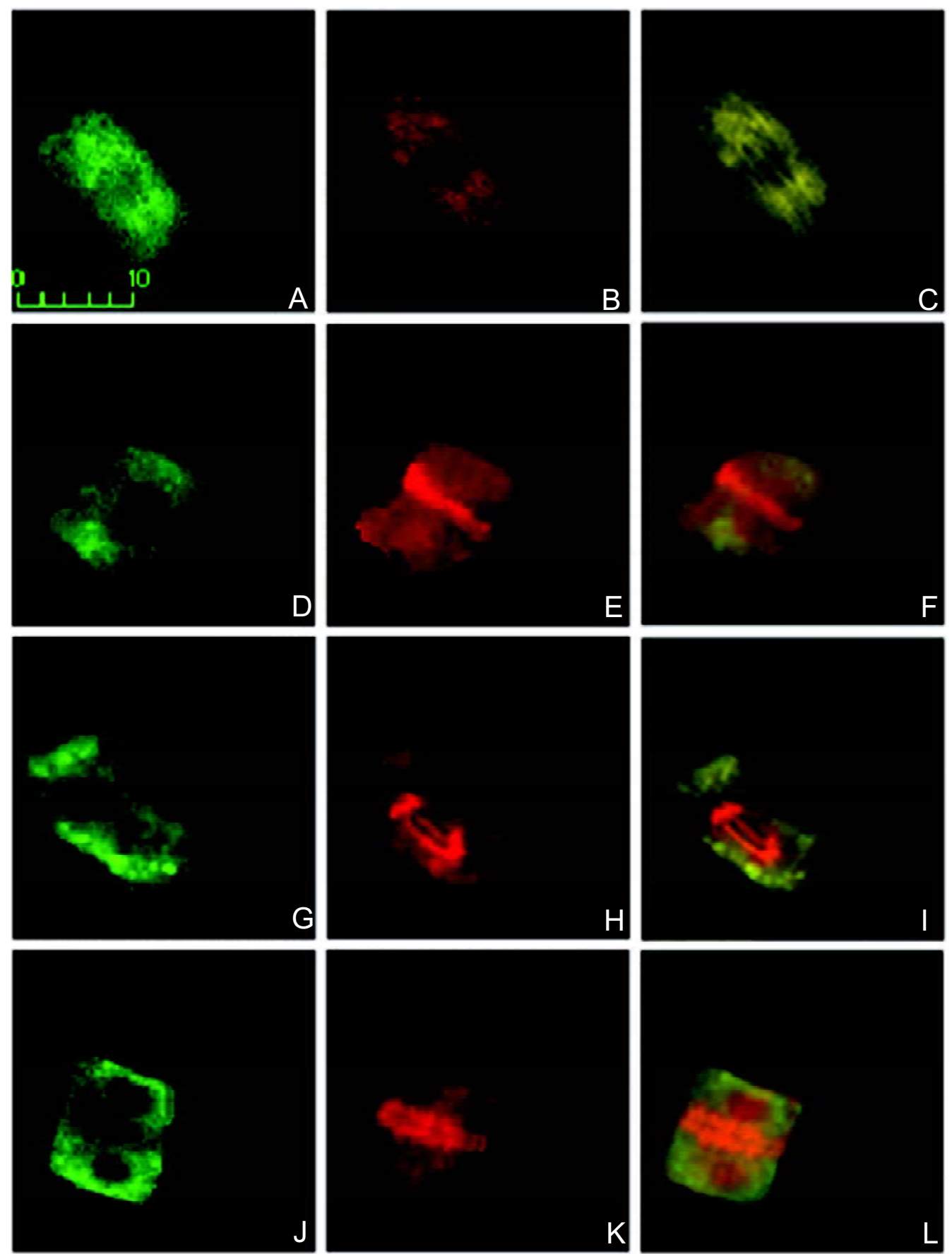

Fig. 3 Dual localization of AtKP1 and microtubules in root tip cells of Arabidopsis. Localization of AtKP1 stained with affinitypurified AtKP1 antibody (A, D, G, J), and microtubules stained with anti- $\beta$-tubulin antibody $(\mathbf{B}, \mathbf{E}, \mathbf{H}, \mathbf{K})$ are shown in root tip cells at interphase (A-C), preprophase (D -F), metaphase (G-I), and telophase (J-L). Composite images (C, F, I, L) are pseudocolored with AtKP1 shown in green and $\beta$-tubulin shown in red. Bars $=10 \mu \mathrm{m}$.

fraction determined by measuring the marker enzymes cytochrom c oxidase for mitochondria, IDPase for Golgi apparatus, catalase for peroxisomes, and chlorophyll for chloroplast (Fig. 4B). When the isolated mitochondria were incubated in a $0.6 \mathrm{M}$ KI solution, AtKP1 could not be re- leased into the supernatant, indicating that AtKP1 is tightly bound to mitochondria (Fig. 4A, lane 12 and 13).

To know whether AtKP1 is also present in chloroplast, we specially isolated chloroplast from Arabidopsis leaves according to Ellis and Hartley [27]. The results from SDS- 
A

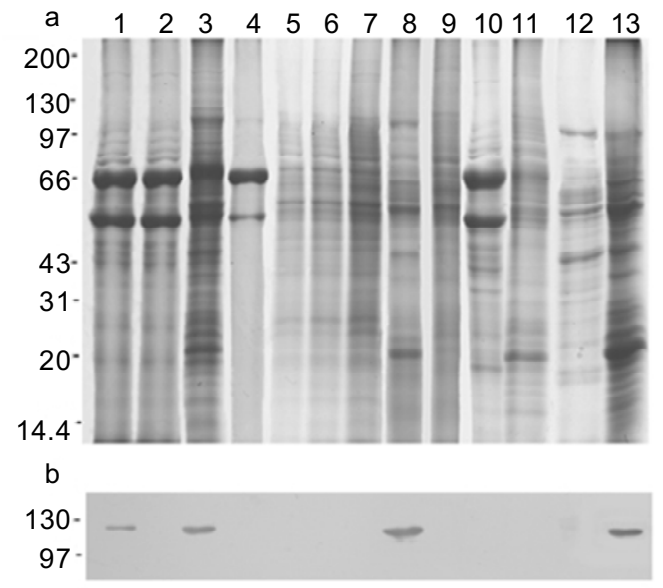

B
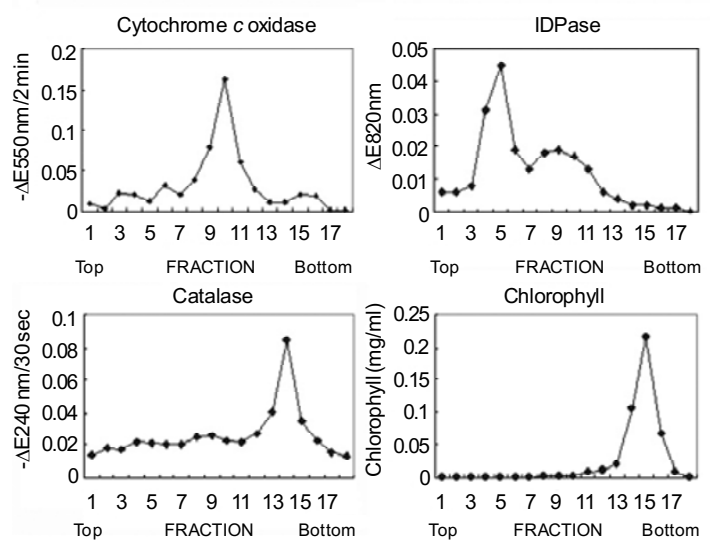

Fig. 4 Western blot analysis of AtKP1 in subcellular fractions isolated from Arabidopsis leaves. (A) Coomassie blue-stained gel (a) and western blots of subcellular fractions probed with the affinitypurified anti-AtKP1 antibody (only the region of the blot corresponding to the kinesin polypeptides is shown, b). The positions of the molecular mass markers (in kilodaltons) are indicated on the left. Lane 1, 2,600×g-supernatant (total homogenate); Lane 2, 12,000×gsupernatant; Lane 3, 12,000 $\times$ g-pellet (crude mitochondria preparation); Lane 4, supernatant in sucrose density gradient; Lanes $5,6,7,9$, the subcellular fractions at the supernatant/0.6M, 0.6/0. $9 \mathrm{M}, 0.9 / 1.2 \mathrm{M}$, and $1.45 / 1.8 \mathrm{M}$ interzone in sucrose density gradient, respectively; Lane 8, mitochondria (the subcellular fraction at the 1. 2/1.45M interzone in sucrose density gradient); Lane 10, cytosol; Lane 11, microsomes; Lane 12, KI-washed mitochondria supernatant; Lane 13, KI-washed mitochondria pellet. (B) Activity assay of cytochrome $c$ oxidase, IDPase, catalase, and chlorophyll in subcellular fractions from Arabidopsis leaves. Fractions each in $2 \mathrm{ml}$ were eluted from the sucrose density gradient and the activity of all marker enzymes was assayed. Fractions 5, 10, 14 shown in Fig. 4B represent subcellular fractions from the $0.6 / 0.9 \mathrm{M}, 1.2 / 1.45 \mathrm{M}$ and $1.45 / 1$. $8 \mathrm{M}$ interzones in sucrose density gradient, respectively.

PAGE and western blot indicated that no positive band corresponding AtKP1 was detected (data not shown).

\section{DISCUSSION}

We report here a specific localization of a kinesin-like protein AtKP1 to mitochondria of Arabidopsis. We took extensive precautions to ensure the specificity of our prepared antibody. First, the selection of AtKP1 specific region used as antigen was based on the Blast Similarity Searches at TAIR (http://www.arabidopsis.org/blast), and the antibody raised against the specific polypeptides was purified with affinity chromatograph method [19]. Second, we prepared the E. coli lysate containing AtKP1-specific polypeptide or entire AtKP1 to identify the specificity of the antibody. When subjected to immunoblotting with affinity-purified AtKP1 antibody, and another two kinds of commercial monoclonal antibodies including anti$6 \times$ histidine antibody and anti-kinesin antibody, both lysates produced only a single immunoreactive band with a molecular weight of $28 \mathrm{kDa}$ or $125 \mathrm{kDa}$ (Fig. 1B). No corresponding band was detected in lane 2 (Fig. 1B) for the reason that the commercial monoclonal anti-kinesin antibody could not recognize the unique polypeptides of AtKP1, demonstrating that our affinity-purified antibody is only specific to AtKP1. Immunoblots of Arabidopsis seedling extract showed that the antibody produced a single immunoreactive band (Fig. 1A, lane c), further indicating the high specificity of our affinity-purified AtKP1 antibody.

Arabidopsis root tip is liable for immunofluorescent labeling, because single whole cells in different mitotic phases are easily obtained. In isolated root tip cells, AtKP1 antibody stained organelle-like structures (Fig. 3) that were identified as mitochondria by subcellular fractionation and Western blot (Fig. 4). Mitochondria are cytoplasmic organelles of eukaryotic cells. Their morphology and dynamics are controlled genetically [28]. Several animal kinesin heavy chains or KLPs have been implicated in the movement of mitochondria, such as the N-terminal motors KIF1B and KIF5B in mouse cells [29, 30], and the KLP67A with N-terminal extension in early Drosophila embryos [31]. In plant cells, transport of mitochondria has been shown to rely on actin filaments $[32,33]$. However, microtubules have also been shown to have a role in the positioning and/or tethering of mitochondria [33]. By using GFP (green fluorescence proteins) fusion and transient expression in tobacco leaf cells, Itoh et al identified two Arabidopsis proteins (MKRP1 and MKRP2, a new subclass of KLPs that contain an N-terminal mitochondrial targeting signal) within mitochondria where microtubules are absent, and suggested that the Arabidopsis MKRPs are involved in the segregation of mitochondrial nucleoids [18].

Many plant KLPs have been localized on preprophase band, mitosis spindle, or phragmoplast [10, 16, 34-37]. At least eight Arabidopsis KLPs are known to function in 
A

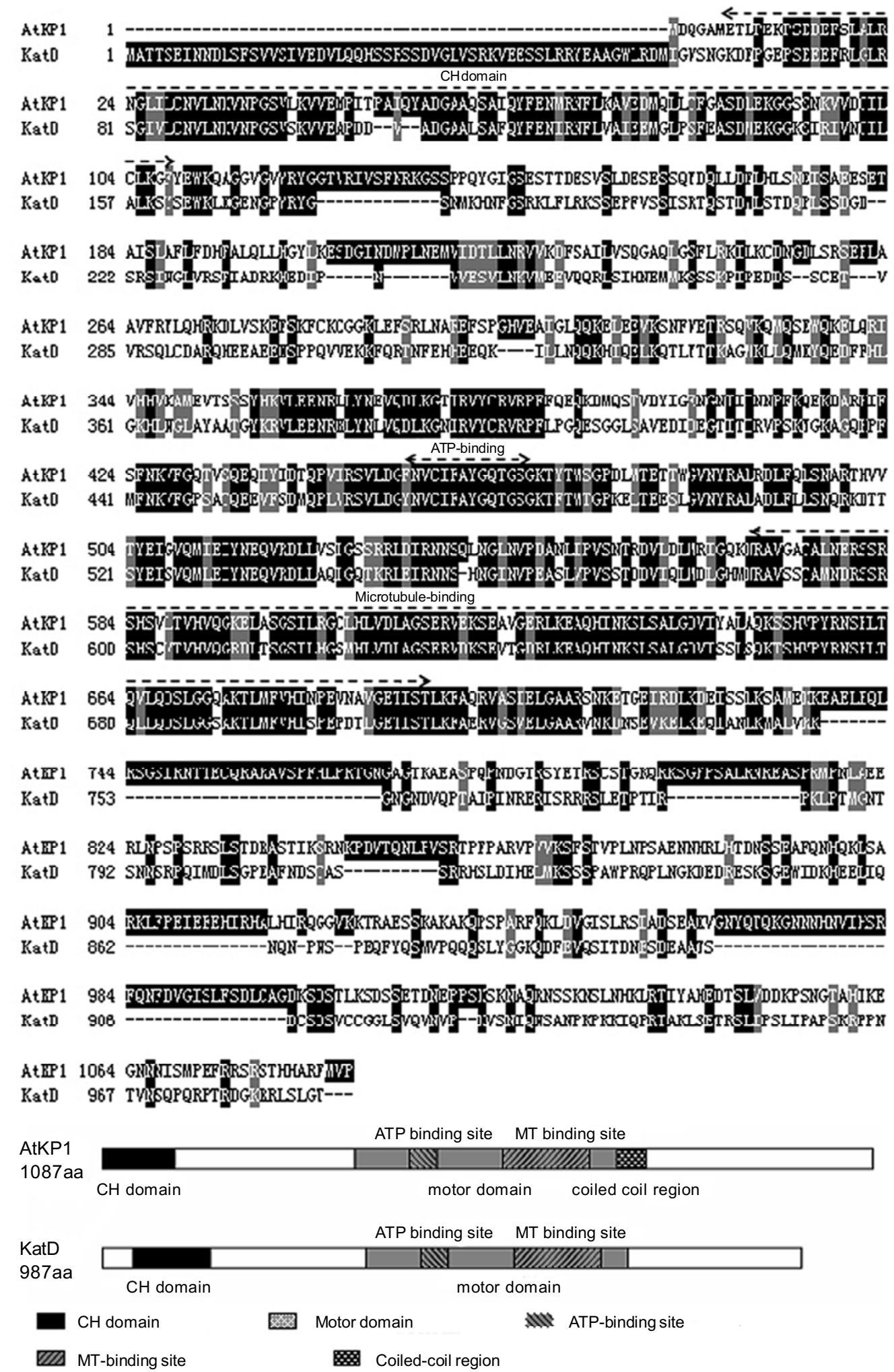

Fig. 5 Sequence and domain comparison of AtKP1 with KatD. (A) Sequence alignment of AtKP1 with KatD using BOXSHADE3.21 (http://www.ch.embnet.org/software/BOX_form.html). The identical amino acid residues for both sequences were highlighted with black background and the conserved amino acid residues were shaded. Gaps introduced into the sequences to optimize alignment are indicated by dashes. The $\mathrm{CH}$-domain, ATP-binding consensus sequence and the putative microtubule (MT)-binding module are indicated by a dashed line above the sequences. (B) Schematic diagram for domain comparison between AtKP1 and KatD using SMART (http://smart.embl-heidelberg.de/), indicating that AtKP1 has a deduced coiled-coil region following its motor domain. 
some aspects of cell division [4]. The results from our dual immunofluorescent labeling show that AtKP1 does not correlate with spindle function (Fig. 3). AtKP1 is widely expressed in seedlings, roots, stems, leaves and flowers, as ascertained with an antibody raised against specific polypeptides of AtKP1 (Fig. 2). Although AtKP1 and KatD [13] have similar structures: their motor domains share $70.9 \%$ amino acid sequence identity, and their N-terminal regions have a similar single $\mathrm{CH}$ (calponin homology) domain which was originally found in actin-crossing link proteins [38]. (Fig. 5A), their expression patterns are very different. KatD is specifically expressed in flowers [13]. The detail domain comparison indicates that AtKP1 has a short coiled-coil region following its motor domain (Fig. 5B). The differences in expression patterns and domain structures suggest that AtKP1 and KatD might have different functions. AtKP1 was expressed in almost all Arabidopsis tissues, except in 28-day-old siliques (Fig. 2). One of the possible explanations is that AtKP1 might contribute mostly to some kind of tissues active in growth or development.

In summary, a new Arabidopsis KLP, AtKP1 with the highest similarity to KatD, is widely expressed in tissues, and tightly bind to mitochondria.

\section{ACKNOWLEDGMENTS}

We are most grateful to Dr. Gregory S MAY (University of Texas) and Dr. Dong Tao REN (China Agricultural University) for their critical reading. This research was supported by grants from the National Natural Science Foundation of China (Project No. 30421002, 30170457, 30370708) and from the Ministry of Science and Technology of China (Project No. JY03-A-03). We thank Dr. Yi Min LIU for technical assistance with the Confocal Microscopy.

Received, Mar 5, 2005

Revised Sep 8, 2005

Accepted, Sep 15, 2005

\section{REFERENCES}

1 Goldstein LSB, Philip AV. The road less traveled: Emerging principles of kinesin motor utilization. Annu Rev Cell Dev Biol 1999; 15:141-83.

2 Reddy ASN. Molecular motors and their functions in plants. Int Rev Cytol 2001; 204:97-178.

3 Hirokawa N, Noda Y, Okada Y. Kinesin and dynein superfamily proteins in organelle transport and cell division. Curr Opin Cell Biol 1998; 10:60-73.

4 Reddy ASN. Molecular motors in plant cells. In: Schliwa M, ed. Molecular Motors. Wiley-VCH Press: Weinheim, Germany 2003: 433-69.

5 Verhey KJ, Meyer D, Deehan R, et al. Cargo of kinesin identi- fied as JIP scaffolding proteins and associated signaling molecules. J Cell Biol. 2001; 152:959-70.

6 Cai G, Bartalesi A, Del Casino C, et al. The kinesin-immunoreactive homologue from Nicotiana tabacum pollen tubes: Biochemical properties and subcellular localization. Planta 1993; 191:496506

7 Tiezzi A, Moscatelli A, Cai G, Bartalesi A, Cresti M. An immunoreactive homolog of mammalian kinesin in Nicotiana tabacum pollen tubes. Cell Motil Cytoskel 1992; 21:132-7.

8 Reddy ASN, Day IS. Kinesins in Arabidopsis: a comparative analysis among eukaryotes. BMC Genomics 2001; 2:2.

9 Vale RD. The molecular motor toolbox for intracellular. Cell 2003; 112:467-80.

10 Mitsui H, Yamaguchi-Shinozaki K, Shinozaki K, Nishikawa K, Takahashi H. Identification of a gene family $(k a t)$ encoding kinesinlike proteins in Arabidopsis thaliana and the characterization of secondary structure of KatA. Mol Gen Genet 1993; 238:362-8.

11 Mitsui H, Nakatani K, Yamaguchi-Shinozaki K, et al. Sequencing and characterization of the kinesin-related genes katB and katC of Arabidopsis thaliana. Plant Mol Biol 1994; 25:865-76.

12 Mitsui HS, Hasezawa TN, Nagata T, Takahashi H. Cell cycledependent accumulation of a kinesin-like protein, Kat B/C, in synchronized tobacco BY-2 cells. Plant Mol Biol 1996; 30:17781.

13 Tamura K, Nakatani K, Mitsui H, Ohashi Y, Takahashi H. Characterization of $k a t D$, a kinesin-like protein gene specifically expressed in floral tissues of Arabidopsis thaliana. Gene 1999; 230:23-32.

14 Reddy ASN, Safadi F, Narasimhulu SB, Golovkin M, Hu.X. A novel plant calmodulin-binding protein with a kinesin heavy chain motor domain. J Biol Chem 1996; 271:7052-60.

15 Wang W, Takezawa D, Narasimhulu SB, Reddy ASN, Poovaiah BW. A novel kinesin-like protein with a calmodulin-binding domain. Plant Mol Biol 1996; 31:87-100.

16 Lee YRJ, Liu B. Identification of a phragmoplast-associated kinesin-related protein in higher plants. Curr Biol 2000; 10:797800.

17 Lee YRJ, Giang HM, Liu B. A novel plant kinesin-related protein specifically associates with the phragmoplast organelles. Plant Cell 2001; 13:2427-39.

18 Itoh R, Fujiwara M, Yoshida S. Kinesin-related proteins with a mitochondrial targeting signal. Plant Physiol 2001; 127:724-6.

19 Olmeted JB. Affinity purification of antibodies from diazotized paper blots of heterogeneous protein samples. J Biol Chem 1981; 256:11955-7.

20 Laties GG. Isolation of Mitochondria from Plant Material. In: Fleischer S, Packer L, eds. Methods in Enzymology. Academic Press: New York 1974: 589-600.

21 Robinson DG, Hinz G. Organelle isolation. In: Hawes C, SatiatJeunemaitre B, eds. Plant Cell Biology, Oxford University Press: Oxford 2001:295-323.

22 Arnon DI. Copper enzyme in isolated chloroplasts. Plant Physiol 1949; 24:1-15.

23 Khodjakov A, Lizunova EM, Minin AA, Koonce MP, Gyoeva FK. A specific light chain of kinesin associates with mitochondria in cultured cells. Mol Biol Cell 1998; 9:333-43.

24 Schroer TA, Schnapp BJ, Reese TS, Sheetz MP. The role of kinesin and other soluble factors in organelle movement along microtubules. J Cell Biol 1988; 107:1785-92. 
25 Palevitz BA. Cytochalasin-induced reorganization of actin in Allium root cells. Cell Motil Cytoskeleton 1988; 9:283-98.

26 Laemmli UK. Cleavage of structural proteins during the assembly of the head of bacteriophage T4. Nature 1970; 227:680-5.

27 Ellis RJ, Hartley MR. Preparation of higher plant chloroplasts active in protein and RNA synthesis. In: Edelman et al. eds. Methods in chloroplast molecular biology. Elsevier Biomedical Press: Oxford 1982:169-88.

28 Logan DC, Scott I, Tobin AK. The genetic control of plant mitochondrial morphology and dynamics. Plant J 2003; 36:500-9.

29 Nangaku M, Sato-Yoshitake R, Okada Y, et al. KIF1B, a novel microtubule plus end-directed monomeric motor protein for transport of mitochondria. Cell 1994; 79:1209-20.

30 Tanaka Y, Kanai Y, Okada Y, et al. Targeted disruption of mouse conventional kinesin heavy chain, kif5B, results in abnormal perinuclear clustering of mitochondria. Cell 1998; 93: 1147-2258

31 Pereira AJ, Dalby B, Stewart RJ, Doxsey SD, Goldstain LSB. Mitochondrial association of a plus-end directed microtubule motor expressed during mitosis in Drosophila. J Cell Biol 1977; 136: $1081-90$
32 Olyslaegers G, Verbelen JP. Improved staining of F-actin and colocalization of mitochondria in plant cells. J Microsc 1998; 192: 73-7.

33 Van Gestel K, Kohlar RH, Verbelen JP. Plant mitochondria move on F-actin, but their positioning in the cortical cytoplasm depends on both F-actin and microtubules. J Exp Bot 2002; 53: 659-67

34 Liu B, Cyr RJ, Palevitz BA. A kinesin-like protein, KatAp, in the cells of Arabidopsis and other plants. Plant Cell 1996; 8:119-32.

35 Smirnova E, Reddy ASN, Bowser J, et al. A minus end-directed kinesin-like motor protein, KCBP, localizes to anaphase spindle poles in Haemanthus endosperm. Cell Motil Cytoskeleton 1998; 41:271-80

36 Vos JW, Safadi F, Reddy ASN, Hepler PK. The kinesin-like calmodulin binding protein is differentially involved in cell division. Plant Cell 2000; 12:979-90.

37 Nishihama R, Soyano T, Ishikawa M, et al. Expansion of the cell plate in plant cytokinesis requires a kinesin-like protein/ MAPKKK complex. Cell 2002; 109:87-99.

38 Castresana J, Saraste M. Does Vav bind to F-actin through a CH domain? FEBS Letter 1995; 374:149-51.

Edited by Bernd MUELLER-ROEBER 